\title{
Thermodynamics of an austentic stainless steel (AISI-348) under in situ TEM heavy ion irradiation
}

\author{
Matheus A. Tunes ${ }^{\mathrm{a}, *}$, Graeme Greaves ${ }^{\mathrm{b}}$, Thomas M. Kremmer ${ }^{\mathrm{a}}$, Vladimir M. Vishnyakov ${ }^{\mathrm{b}}$, Philip D. \\ Edmondson $^{c}$, Stephen E. Donnelly ${ }^{\mathrm{b}}$, Stefan Pogatscher ${ }^{\mathrm{a}}$, Cláudio G. Schön ${ }^{\mathrm{d}}$ \\ ${ }^{a}$ Chair of Nonferrous Metallurgy, Montanuniversitaet Leoben, Austria \\ ${ }^{b}$ School of Computing and Engineering, University of Huddersfield, United Kingdom \\ ${ }^{c}$ Oak Ridge National Laboratory, Materials Sciences and Technology Division, United States of America \\ ${ }^{d}$ Department of Metallurgical and Materials Engineering, Escola Politécnica, University of São Paulo, Brazil
}

\begin{abstract}
The stability of the face-centred cubic austenite $(\gamma$-Fe) phase in a commercial stainless steel (AISI348) was investigated through in situ transmission electron microscopy (TEM) with heavy ion irradiation at $1073 \mathrm{~K}$ up to a fluence of $1.3 \times 10^{17} \mathrm{ions} \cdot \mathrm{cm}^{-2}$ (corresponding to a dose of $46 \mathrm{dpa}$ ). The $\gamma$-Fe phase was observed to decompose at a fluence of around $7.8 \times 10^{15}$ ions $\cdot \mathrm{cm}^{-2}$ ( $3 \mathrm{dpa}$ ) when a new phase nucleated and grew upon increasing irradiation dose. Scanning transmission electron microscopy (STEM) with energy dispersive X-ray (EDX) spectroscopy and multivariate statistical analysis (MVSA) were used to characterise the irradiated specimens. The combination of such experimental techniques with calculated equilibrium phase diagrams using the CALPHAD method led to the conclusion that the new phase formed upon irradiation is the body-centred cubic Cr-rich $\alpha^{\prime}$ phase. At the nanoscale, precipitation of $\mathrm{M}_{23} \mathrm{C}_{6}$ ( $\tau$-carbide) was also observed. The results indicate that ion irradiation can assist the austenitic stainless steel to reach a non-equilibrium state similar to a calculated equilibrium state observed at lower temperatures in which, under conventional conditions, is suppressed due to kinetic restrictions.
\end{abstract}

Keywords: Austenitic Stainless Steels, Radiation Damage, Radiation Induced Segregation, In situ TEM ion implantation, CALPHAD

\section{Introduction}

The reliability of nuclear power systems depends on the performance of structural materials whose degradation and failure may be caused by several aspects of the harmful environment within a nuclear reactor [1-3]. In particular, nuclear fuel-cladding systems are subjected to high neutron fluxes with a broad energy spectrum. The resulting displacement of lattice atoms may induce permanent microstructural defects under in-service conditions giving rise to a modified material with degraded mechanical properties [3, 4].

During the last century, improved fundamental understanding of irradiation-induced damage in a wide variety of materials has led to the development of conventional nuclear materials such as $\mathrm{Zr}$ - and

\footnotetext{
*Corresponding author:

Email address: matheus. tunes@unileoben.ac . at (Matheus A. Tunes)
} 
Ni-based alloys, and several types of stainless steels [3, 5, 6]. On the latter, austenitic stainless steels were used as nuclear fuel cladding alloys at the beginning of the light-water reactors technology in the 1960s [7] and have been also considered for structural components in innovative nuclear fusion test reactors due to their remarkable track-record of successful applications in extreme environments [8-10]. The 300 series steels (Fe-Cr-Ni alloy) possess excellent corrosion and mechanical properties for applications at high temperatures which makes them viable to be applied in aeroengine parts, turbochargers, oil and gas pipelines [11-24] and as structural components in nuclear reactors [7, 8, 19]. In order to improve the stabilisation of the $\gamma$-Fe phase at room temperature, either interstitials elements such as $\mathrm{C}$ and $\mathrm{N}$ or substitutional such as $\mathrm{Mn}, \mathrm{Co}, \mathrm{Ti}, \mathrm{Nb}, \mathrm{V}, \mathrm{W}, \mathrm{Cu}$ and $\mathrm{Al}$ are used which also impact the microstructure and mechanical properties [12, 14, 19, 25].

Despite their favourable properties which include good corrosion resistance at high temperatures and lower cost as compared with Zr-based alloys, the thermodynamic stability of the austenite phase is still a subject of intense research [13-16] in particular, the response and microstructural evolution of the austenite phase in environments where energetic displacive irradiation is a concern [26]. The exposure to displacive irradiation generates a series of undesired effects such as radiation-induced precipitation (RIP) and segregation (RIS) [19, 26-28]. These effects combined are reported to induce the decomposition of the $\gamma$-Fe phase into a non-equilibrium thermodynamic state with considerable loss of structural integrity during nuclear reactor operation [19, 26-28].

Within the wide range of different steels grades in the 300 series, the AISI 304, 316 and 347 were extensively investigated due to their relevance for the nuclear technology applications, as reviewed by Lucas [8]. Several works have been aimed at investigating the occurrence of RIS and RIP as an effect of particle irradiation in such steels. In 1960s, Arkell et al. were pioneers in detecting the effects of neutron irradiation at $1073 \mathrm{~K}$ in the ternary alloy Fe-20Cr-25Ni (\%wt.) stabilized with minor $\mathrm{Nb}$ additions. Post-irradiation analysis of electropolished thin-foils in a TEM revealed the secondary phases precipitation in the matrix and along the grain boundaries. Although such secondary phases (or precipitates) were not identified by the authors, their formation contributed to reduce the ductility of steel as assessed via tensile tests [29].

Additional studies on the RIS and RIP phenomena were carried out by Anthony [30] in early 1970s. He investigated the effects of particle irradiation in metals concluding that segregation was caused by supersaturated vacancy flux into irradiation-induced voids. The solute-enrichment effect was believed to occur by means of vacancy-solute binding effects. The author also estimated that Cr, Mo and Si diffuse faster than Fe. Diffusion of Ni was suppressed. Okamoto et al. [31, 32] experimentally observed solute enrichment at sinks in several binary and ternary alloys due to the binding effect with vacancies, as proposed by Anthony [30]. The authors also reported on strain effects at voids that lead to RIP in steels. Sethi et al. [33] measured the elemental composition profiles of the irradiated AISI 316 and showed that while Ni and Si enriches the surface of the sample, $\mathrm{Cr}$ and Mo were depleted.

Later, Okamoto and co-workers [34] investigated the effects of electron irradiation and ion bombardment in the Fe-18Cr-8Ni-1Si (\%wt.) austenitic steel. They observed that strain fields around voids changed the precipitation kinetics. By means of using analytical electron microscopy (AEM), 
the authors also found $\mathrm{Si}$ - and Ni-rich areas at sinks, which was considered a direct observation of the RIS phenomenon. Maziasz identified the formation of $\mathrm{Ni}_{3} \mathrm{Si}$, the $\mathrm{G}$ phase and several phosphides in the AISI 316 stainless steel under neutron irradiation from 5 to 125 dpa within the range from 573 to $973 \mathrm{~K}$ [35]. In another similar study with the AISI 316 steel [36], the same author concluded that the $\mathrm{He} / \mathrm{dpa}$ ratio plays a major role in suppressing RIS by means of reducing the radiation-induced phase formation as He bubbles, that are formed after transmutation reactions (mainly due to Ni decay). The bubbles can act as sinks for vacancies during irradiation. Allen et al. [37] analysed the influence of $\mathrm{Ni}$ addition in the system Fe-16-18Cr-xNi (\%wt) under $3.2 \mathrm{MeV}$ proton irradiation up to 1 dpa at $673 \mathrm{~K}$. The authors showed that upon increasing Ni concentration, a significant reduction in swelling with a subsequent increase in segregation was observed. Additionally, minor additions of Mo and $\mathrm{P}$ eliminated swelling and reduced RIS considerably. It was suggested that the generation of point defects in excess levels as a result of the irradiation, enhances thermal precipitation by several orders of magnitude: this shows an intrinsic connection between the thermodynamics of alloy systems with the RIS phenomenon.

Recently, Jiao et al. [38] observed the formation of $\mathrm{Ni}$-, $\mathrm{Si}$ - and $\mathrm{Cu}$-rich areas as a direct result of RIS promoted by $2 \mathrm{MeV}$ protons up to $2 \mathrm{dpa}$ at $633 \mathrm{~K}$. The authors also detected elemental segregation at grain boundaries. The analysis was performed by using Atom Probe Tomography. In a recent ion irradiation study with $120 \mathrm{keV}$ Ar at $823 \mathrm{~K}$, Jin et al. [39] reported on the RIP of $\mathrm{M}_{23} \mathrm{C}_{6}$ preferentially at dislocation loops in a austenitic steel with $\mathrm{Fe}-24.8 \mathrm{Cr}-19.7 \mathrm{Ni}-0.4 \mathrm{Nb}-0.4 \mathrm{Mn}$ (\%wt.) composition and minor additions of $\mathrm{Si}, \mathrm{N}, \mathrm{C}, \mathrm{P}$ and $\mathrm{S}$. The nucleation and growth of $\mathrm{M}_{23} \mathrm{C}_{6}$ precipitates in the AISI-348 was also reported to occur under heavy ion irradiation with in situ TEM in another recent study [40]. Shim et al. [27] reported that calculations based on classical nucleation theory and the thermodynamic extremum principle indicated that the $\gamma^{\prime}$ and the $G$ are the dominant irradiation-induced phases in a Ti-stabilised AISI 316 steel. These authors also concluded that the $\mathrm{G}$ phase is relatively dominant over the $\gamma^{\prime}[27]$.

In summary, different phases and precipitates were observed in the decomposition of irradiationdamaged austenitic stainless steel either due to a synnergistic effect of thermal annealing and either neutron, electron or ion irradiation [8, 26, 41-46]. In austenitic stainless steels, both RIS and RIP (either neutron- or ion-induced) often occur in the temperature range from 573 to $1100 \mathrm{~K}$ with doses varying from $2 \mathrm{dpa}$ to $40 \mathrm{dpa}$. From a microstructural perspective, the distinction between thermal annealing, RIS and RIP in austenitic stainless steels was a subject of intense debate in the history of nuclear materials development. In general, theoretical developments and experiments have indicated so far that due to the introduction of point defects at supersaturated levels, the irradiation enhances atomic mobility and diffusion. As a consequence, segregation of alloying elements, nucleation and growth of new phases and precipitation will occur faster when compared with thermal processes. Additionally, it has been reported that the phases formed due to irradiation often differ from equilibrium phases with respect to their elemental compositions [26].

In the present work, a commercial austenitic stainless steel, the AISI-348, was irradiated with $30 \mathrm{keV} \mathrm{Xe}$ ions in situ within a TEM at $1073 \mathrm{~K}$ up to a fluence of $1.3 \times 10^{17}$ ions $\cdot \mathrm{cm}^{-2}$ which corresponds to $46 \mathrm{dpa}$. Ion irradiation with heavy inert gases has been used to assess the radiation 
resistance of multicomponent Fe-based alloys as it promotes substantial displacement damage per ion collision [47]. According to Garner et al. [48], the radiation data on AISI-348 is still scarce and, in some cases, not available in the scientific literature. Although there is substantial neutron and ion irradiation data for AISI 316 [48] which is a very similar steel to the AISI-348, the majority of the available data is on lower neutron exposure levels [49-51]. We report on the in situ TEM observation of a radiation-induced phase transformation (induced by ion irradiation) in the AISI-348 steel. Post-irradiation characterisation using a combination of different techniques such as TEM, scanning transmission electron microscopy (STEM), energy dispersive X-ray spectroscopy (EDX) and multivariate statistical analysis (MVSA) from the obtained EDX spectra, led to the conclusion that the initial $\gamma$-Fe phase decomposed into the $\mathrm{Cr}$-rich $\alpha^{\prime}$ phase. The results are discussed within the current theoretical models on RIP and elemental segregation as well as with previous similar works in $\mathrm{Fe}-\mathrm{Cr}$ [52-56] and Fe-Cr-Al [57-59] alloys. Therefore, the results herein presented are also compared with the equilibrium phase diagrams calculated using the CALPHAD method.

\section{Materials and Methods}

\subsection{The studied alloy and sample preparation}

According to the American Iron and Steel Institute (AISI), the austenitic stainless steel 348 is an Febased alloy of $19 \mathrm{Cr}-11 \mathrm{Ni}-2 \mathrm{Mn}$ (wt.\%) and it is fully austenitic at room and high temperatures [60]. The austenitic microstructure, however, corresponds to a metastable state which is inherited from the processing (hot rolling) and by the relatively large cooling rates which follow it. The AISI-348 steel belongs to the 300 series of steels and it is comparable to the widely used AISI 316 . The differences lie in the presence of the elements $\mathrm{Nb}$ and $\mathrm{Ta}$ in minor concentrations, that are added into the AISI348 to remove $\mathrm{C}$ from solid solution which prevents sensitization by means of avoiding the formation of $\mathrm{M}_{23} \mathrm{C}_{6}$ carbides preferentially at the grain boundaries [11, 61, 62]].

Table 1: The elemental composition of the austenitic stainless steel AISI- 348 measured by ICP-OES (the error is $\pm 1 \%$ for each value).

\begin{tabular}{|c|c|}
\hline Element & Composition [wt. \%] \\
\hline $\mathbf{C}$ & 0.037 \\
\hline $\mathbf{S}$ & $<0.001$ \\
\hline $\mathbf{P}$ & 0.002 \\
\hline $\mathbf{N i}$ & 9.47 \\
\hline $\mathbf{S i}$ & 0.36 \\
\hline $\mathbf{M n}$ & 1.81 \\
\hline $\mathbf{C r}$ & 17.50 \\
\hline $\mathbf{C o}$ & $<0.001$ \\
\hline $\mathbf{B}$ & $<0.008$ \\
\hline $\mathbf{T a}$ & 0.003 \\
\hline $\mathbf{N b}$ & 0.32 \\
\hline $\mathbf{F e}$ & Balance \\
\hline
\end{tabular}

The chemical analysis on the AISI-348 bulk samples used in this work was performed by the inductively coupled plasma-optical emission spectrometry (ICP-OES) and the results are shown in table 1. 

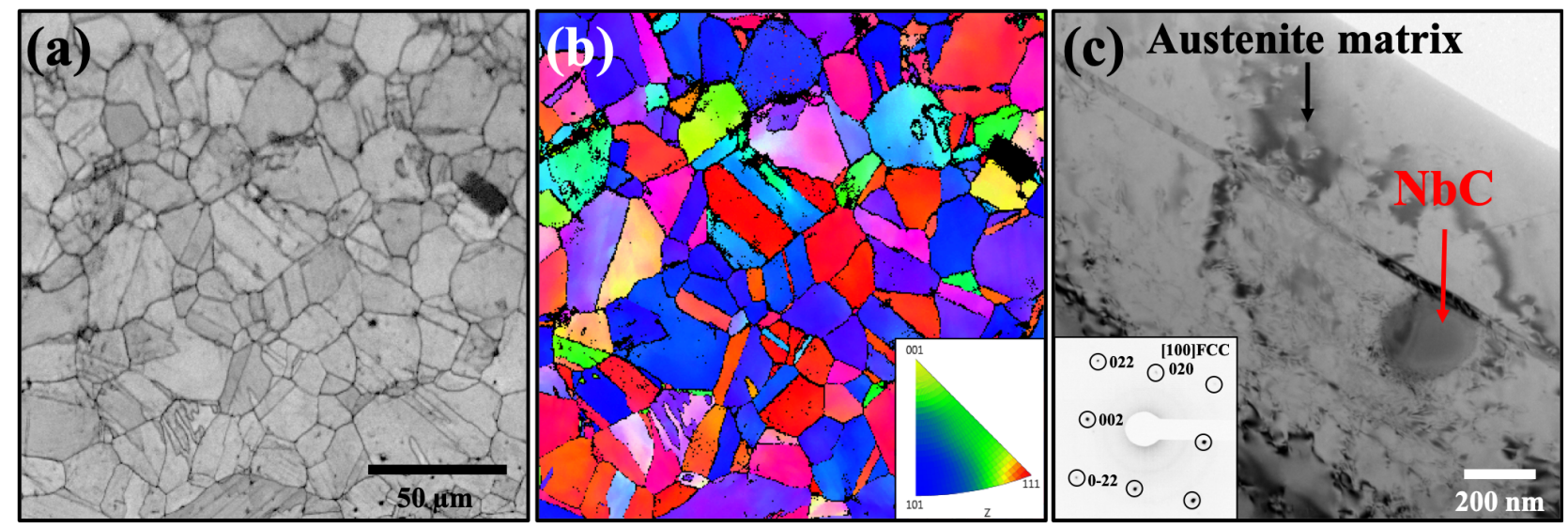

Figure 1: Electron microscopy characterisation of the AISI-348 steel after electropolishing and prior irradiation: (a) an electron-backscattered diffraction (EBSD) band contrast micrograph showing the equiaxed-grain microstructure of the steel, (b) an inverse pole figure along the z-axis and (c) a BFTEM micrograph showing $\gamma$-Fe matrix with a NbC precipitate. The inset in (c) represents an indexed diffraction pattern from the austenite matrix prior to irradiation. Note: the scale bar in (a) also applies in (b).

Disks $3 \mathrm{~mm}$ in diameter and thicknesses of around 150-200 $\mu \mathrm{m}$ were punched from the bulk alloy and mechanically polished using $\mathrm{SiC}$ paper up to a grit of 1200 . The $3 \mathrm{~mm}$ disks were accurately mechanically polished using a tripod polishing stage from PELCOß (model 590TEM) with a set of diamond lapping discs (grit-sizes from 9 to $1 \mu \mathrm{m}$ ). The samples were then electropolished with a Struers TenuPol-5, using an electrolyte consisting of a solution of $90 \%$ perchloric acid $\left(\mathrm{HClO}_{4}\right)$ and $10 \%$ (vol.\%) of methanol $\left(\mathrm{CH}_{3} \mathrm{OH}\right)$. The electrolyte temperature was maintained at $233 \mathrm{~K}$. The flow rate was set to 30 arbitrary units as indicated in the TenuPol-5 display. Electropolishing was carried out until perforation and samples were sequentially washed several times in pure methanol and then dried in air.

A microstructural characterisation of the AISI-348 steel after the electropolishing and before irradiation is shown in figure 1. The electron-backscattered diffraction (EBSD) band contrast micrograph and its inverse pole figure - figures 1(a) and 1(b) - exhibit the equiaxed-grain microstructure of the AISI-348 steel. Bright-Field TEM (BFTEM) micrograph in figure 1(c) shows the presence of NbC precipitates within the microstructure, which is expected as a result of the intentional $\mathrm{Nb}$ addition into the alloy. The inset in figure 1(c) is an indexed diffraction pattern from the austenite matrix prior irradiation. In this work, the diffraction patterns were indexed using the CrystalMaker software with data available in the literature for $\gamma$-Fe [63] and ferrite $(\alpha / \delta$-Fe) [64].

\subsection{In situ TEM ion irradiation at the MIAMI facilities}

Specimens were irradiated with $30 \mathrm{keV}$ Xe ions in situ within a TEM at $1073 \mathrm{~K}\left(0.56 \mathrm{~T}_{m}\right.$, where $T_{m}$ is the estimated melting temperature of the alloy) using a double-tilt heating holder in both MIAMI-1 and -2 facilities at the University of Huddersfield: detailed description of both systems can be found elsewhere [65, 66]. The ion flux was $4.2 \times 10^{13}$ ions $\cdot \mathrm{cm}^{-2} \cdot \mathrm{s}^{-1}$ measured at the specimen position. Images and videos were captured using a JEOL JEM-2000FX TEM operating at $200 \mathrm{kV}$ equipped with a Gatan ORIUS SC200 digital camera (MIAMI-1) and in a Hitachi H-9500 TEM operating at $300 \mathrm{kV}$ equipped with a Gatan OneView digital camera (MIAMI-2). 
SRIM (Stopping and Range of Ions in Matter) was used to calculate the damage profile and convert fluence-to-dpa following a procedure suggested by Stoller et al. [67]. Under such irradiation conditions, SRIM predicts 355 vacancies per ion collision, on average, and the implantation peak is estimated to be located at around $10 \mathrm{~nm}$. The sample was irradiated up to $1.3 \times 10^{17}$ ions $\cdot \mathrm{cm}^{-2}$ which corresponds to $46 \mathrm{dpa}$. BFTEM and selected-area electron diffraction (SAED) were used after irradiation to index the studied phases.

\subsection{Post-irradiation characterisation}

Post-irradiated samples were analysed in the Low-Activation Materials Development and Analysis at the Oak Ridge National Laboratory and at the Montanuniversität Leoben in both cases using a FEI Talos F200X S/TEM operating a field-emission gun at $200 \mathrm{kV}$. EDX was used to collect elemental maps of the irradiated alloy with the STEM. MVSA technique was carried out from the obtained EDX maps in order to identify and differentiate the elements present in the studied phases [45, 68, 69].

\subsection{Thermodynamic calculations}

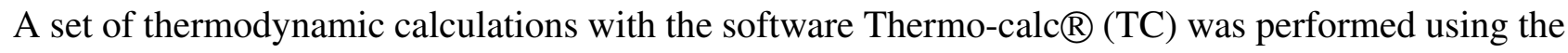
SGTE1 Solid Solution 2.0 database (SSOL2). As discussed in a previous work by one of the authors [70], this is an old database, but it still can be considered reliable for the application to stainless steels. In order to perform the calculations, the system was approximated by a subset of this database corresponding to system $\mathrm{Fe}-\mathrm{C}-\mathrm{Cr}-\mathrm{Ni}-\mathrm{Mn}-\mathrm{Si}-\mathrm{Nb}$ and the A1_FCC, A2_BCC, LIQUID, $\mathrm{M}_{23} \mathrm{C}_{6}$ and SIGMA phases. Both A1_FCC and A2_BCC were described by two sub-sets. In the case of A1_FCC the first sub-set contains a highly defective interstitial sublattice, corresponding to $\gamma$-Fe, and the second subset contains an interstitial sublattice fully occupied by $\mathrm{C}$, corresponding to the $\mathrm{NbC}$-like carbide. In the case of A2_BCC the first sub-set contains a majority of iron (corresponding to ferrite), and the second sub-set contains a majority of $\mathrm{Cr}$, corresponding to $\alpha^{\prime}$ phase. The composition of the steel (as previously reported) was used as input in these calculations. Phase molar fractions $(n p(*))$ and the composition of $\gamma$-Fe and of $\alpha^{\prime}$ were plotted against temperature. For the compositions, it must be noted that the CALPHAD method works with virtual phases [71], therefore a solution is calculated even when the phase is not stable (this is particularly critical for $\alpha^{\prime}$, which is stable only at low temperatures). All calculations were performed at pressure $P=101325 \mathrm{~Pa}(1 \mathrm{~atm})$ and with the whole system containing one mol of atoms. Similar calculations were carried out within the software FactSage [72] using the FSstel database and the results from Thermo-calc were fully reproduced. Such calculations with FactSage were not included in this paper for clarification, but can be found in the Mendeley dataset (section 6) associated with this paper.

\section{Results}

The figure 2 shows a set of low magnification BFTEM micrographs tracking the evolution of the $\gamma$-Fe phase during the in situ TEM heavy ion irradiation. The $\gamma$-Fe phase started to decompose at

\footnotetext{
${ }^{1}$ SGTE represents the Scientific Group Thermodata Europe, a consortium of laboratories in Europe and Canada which is responsible for publishing and keeping standard thermodynamic databases for public use.
} 
a fluence of around $7.8 \times 10^{15}$ ions $\cdot \mathrm{cm}^{-2}$ (3 dpa) where a new phase starts to nucleate in the form of small embryos with brighter contrast when compared with the $\gamma$-Fe matrix.

(a)

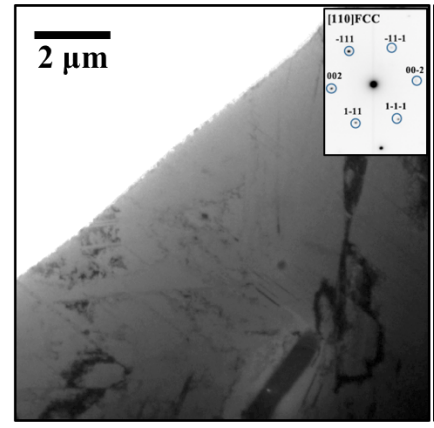

$0 \mathrm{dpa}$ (b)

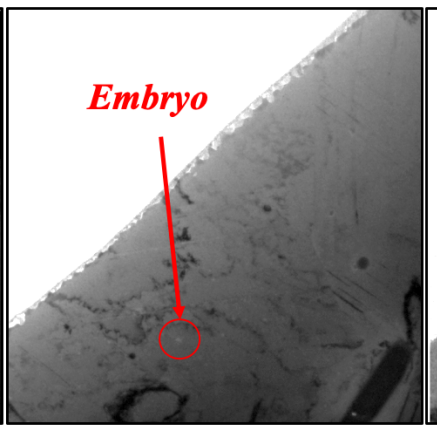

$3 \mathrm{dpa}$

$7.8 \times 10^{15}$ ions $\cdot \mathrm{cm}^{-2}$ (c)

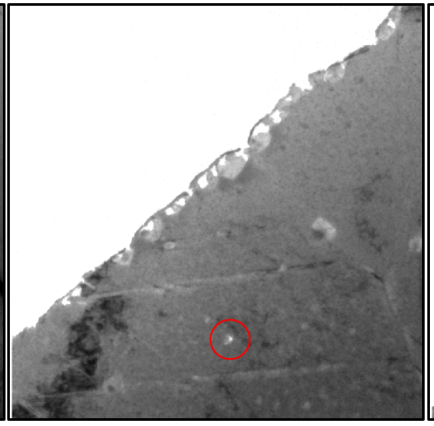

$7 \mathrm{dpa}$

$1.8 \times 10^{16}$ ions $\cdot \mathrm{cm}^{-2}$ (d)

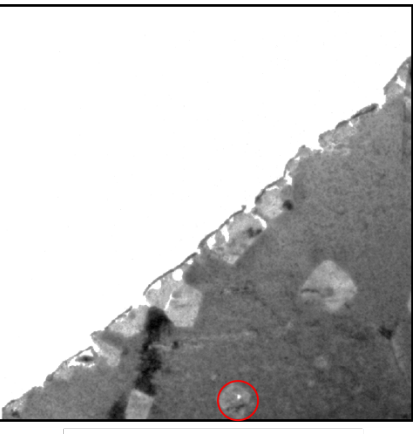

$10 \mathrm{dpa}$

$2.8 \times 10^{16}$ ions $\cdot \mathrm{cm}^{-2}$

Figure 2: The evolution of the $\gamma$-Fe phase during the $30 \mathrm{keV} \mathrm{Xe} \mathrm{irradiation} \mathrm{experiment.} \mathrm{The} \mathrm{BFTEM} \mathrm{micrograph} \mathrm{(a)}$ shows the $\gamma$-Fe before the irradiation and after 20 minutes of annealing at $T=1073 \mathrm{~K}$; micrographs from (b) to (d) exhibit the same area, but at different dose levels. Note: the scale bar in (a) applies to all micrographs in the figure.

Upon increasing the irradiation dose, the radiation-induced phase grew from nanoscale to microscale and its final average size was between 1 to $2 \mu \mathrm{m}$ as shown in the BFTEM micrograph 2(d) after $2.8 \times 10^{16}$ ions $\cdot \mathrm{cm}^{-2}(10 \mathrm{dpa})$ and no significant growth was observed at higher doses as can be seen in the BFTEM micrograph 3 (a) after $1.3 \times 10^{17}$ ions $\cdot \mathrm{cm}^{-2}$ (46 dpa) of irradiation. At the end of the irradiation experiments, a recurrent post-irradiation observation with low-magnification TEM indicated that the damaged samples developed cracks which appear to be intergranular as shown in figure $3(a)$.

At higher magnifications, Xe bubbles and nano-precipitates were observed in both the matrix and the radiation-induced phase as shown in the BFTEM underfocused micrograph in figure $3(\mathrm{~b})$. The crystallographic identification of this radiation-induced phase was carried out using the SAED pattern in the figure 3(c), obtained from the area shown in the inset in figure 3 (b). The new phase is of BCC crystal structure as confirmed by the CrystalMaker model from data available in literature [64] and showed in figure 3(d). Additionally, the satellite spots observable in the diffraction pattern in figure 3.c) were indexed with data available in the literature for $\mathrm{M}_{23} \mathrm{C}_{6}$ precipitates [73].

The low magnification STEM-EDX mapping is presented in figure 4 . The new phase is preferentially formed transgranular within the $\gamma$-Fe equiaxed grains. The $\mathrm{Cr}, \mathrm{Ni}$ and $\mathrm{Mn}$ maps show that this radiation-induced phase is $\mathrm{Cr}$ - and $\mathrm{Mn}$-rich with some $\mathrm{Ni}$, although highly depleted in $\mathrm{Fe}$. Additionally, $\mathrm{Si}$ and Xe tend to migrate into regions where pre-existing NbC particles are observed.

Aiming at further analysing the obtained results from STEM-EDX, the MVSA technique was used. This technique provides accurate identification of multiple phases through segmentation of the high-angle annular dark-field (HAADF) signal, preserving the qualitative EDX elemental information [68]. The use of the MVSA technique in this work resulted in the generation of spectral images along with STEM-EDX spectra for each identified phase. The MVSA results shown in figure 5 correspond to the EDX maps presented in figure 4. The $\gamma$-Fe phase depleted in $\mathrm{Cr}$ was identified as represented by the spectral image in 5(a) and its respective EDX spectrum in figure 5(a1). The spectral image and 

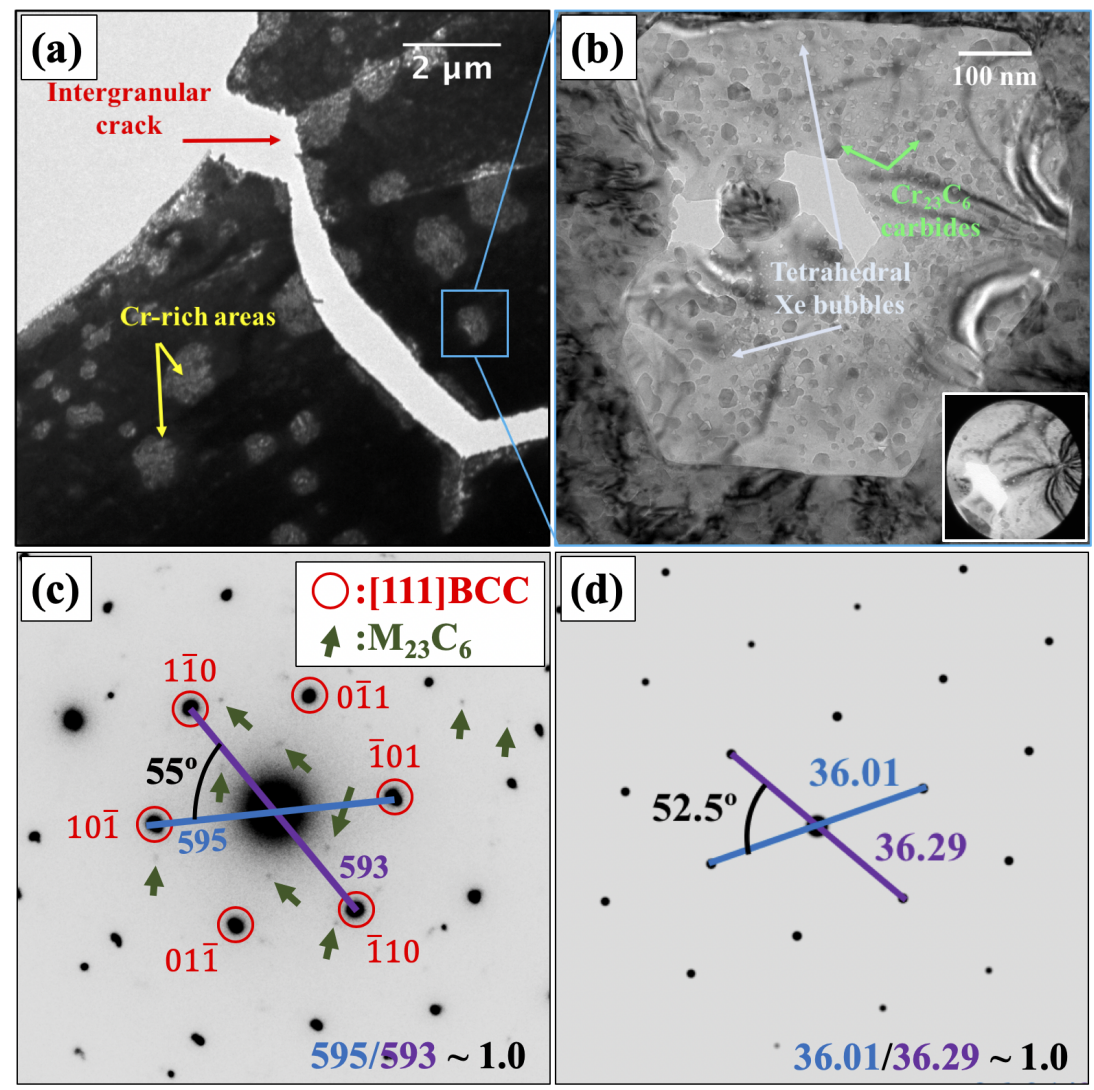

Figure 3: Crystallographic characterisation of the new phase formed during heavy ion irradiation: (a) low magnification BFTEM micrograph showing the $\gamma$-Fe and the new phases after irradiation to $1.3 \times 10^{17}$ ions $\cdot \mathrm{cm}^{-2}$ (46 dpa) and (b) high magnification BFTEM micrograph showing the new phase in detail including nano-precipitates and Xe bubbles. The diffraction pattern in (c) corresponds to the selected-area micrograph presented as an inset in figure (b) where the red circles are the diffraction spots from the matrix and the green arrows are the diffraction spots from the $\mathrm{M}_{23} \mathrm{C}_{6}$ precipitates. The image (d) shows a simulated (with CrystalMaker) diffraction pattern for the $\mathrm{FeCr}$ (BCC) phase from reference [64] which was used to index the DP in (c). Note: micrograph (b) is underfocused (1000 nm).

its EDX spectrum shown in figures 5(b) and 5(b1) correspond to the identification of the radiationinduced Cr-rich $\alpha^{\prime}$ phase. Pre-existing NbC particles were also identified in the MVSA analysis as shown in figures 5 (c) and 5 (c1).

A second STEM-EDX mapping experiment in the surroundings of $\mathrm{NbC}$ particles was performed and the results are shown in figure 6 . These results demonstrate that the formation of the Cr-rich $\alpha^{\prime}$ phase is also prone to occur at grain boundaries between the $\gamma$-Fe and the $\mathrm{NbC}$ particles. The EDX maps in figure figure 6 exhibit the same segregation of $\mathrm{Ni}, \mathrm{Mn}, \mathrm{Si}$ and $\mathrm{C}$ at grain boundaries. In the regions to the $\mathrm{NbC}$, it is noticeable that Xe enriches both grain boundaries and carbides. The qualitative results from the second MVSA analysis shown in the set of images in figure 7 are in good agreement with similar MVSA results presented in figure 5 .

STEM-EDX screening at higher magnifications has shown that the radiation-induced formation of $\mathrm{M}_{23} \mathrm{C}_{6}$ nano-precipitates is prone to occur in regions closer to the pre-existing $\mathrm{NbC}$ particles as exhibited in figure 8. These nano-precipitates were found to be highly enriched in $\mathrm{Cr}$ and $\mathrm{Mn}$, but not highly depleted in $\mathrm{Fe}$ as in the case of the $\mathrm{Cr}$-rich $\alpha^{\prime}$ phase. The $\mathrm{C}$ signal is also (slightly) stronger in the areas where the $\mathrm{M}_{23} \mathrm{C}_{6}$ are found.

The outputs of the thermodynamic calculation are presented in figure 9 . Figure 9 (a) shows phase molar fractions diagrams as a function of temperature. The $\alpha^{\prime}$ phase is stable up to around $700 \mathrm{~K}$, 


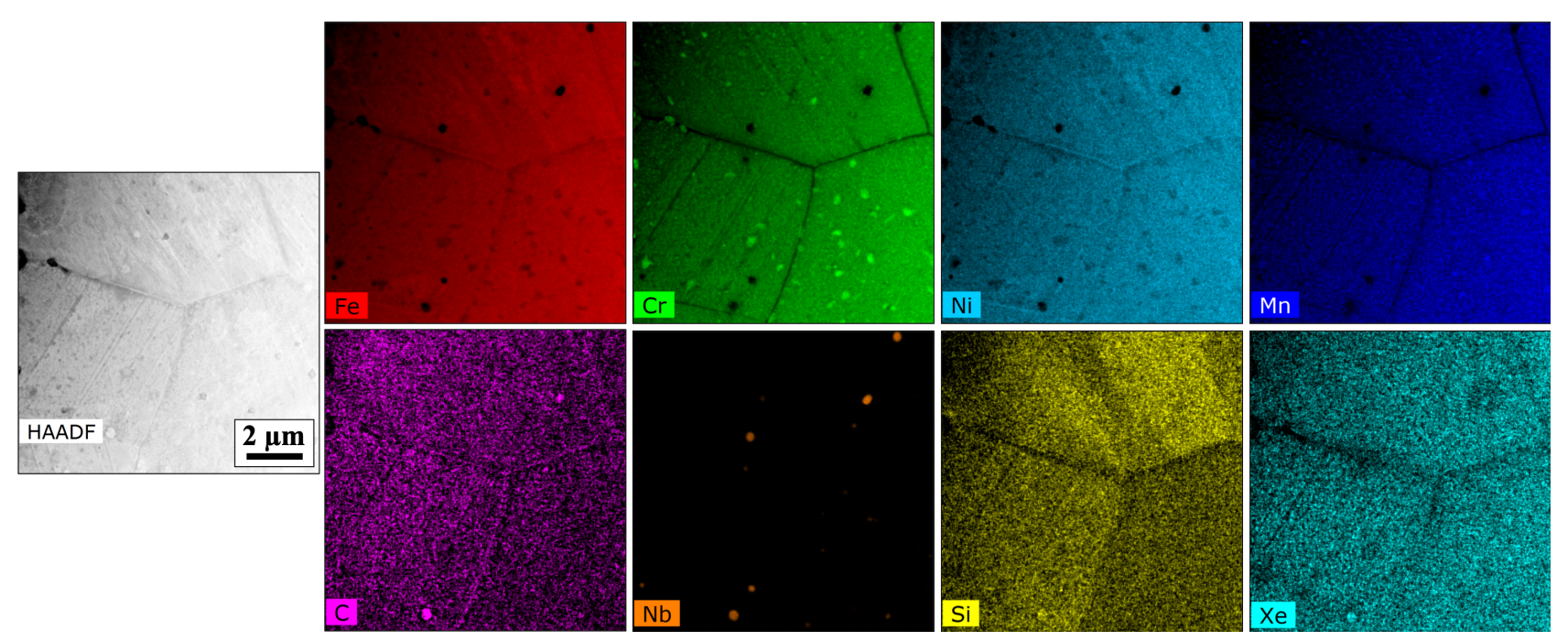

Figure 4: Low magnification STEM-EDX maps obtained from the AISI-348 steel irradiated up to $1.3 \times 10^{17}$ ions $\cdot \mathrm{cm}^{-2}$ (46 dpa) at $1073 \mathrm{~K}$ with $30 \mathrm{keV} \mathrm{Xe}$ ions. The Cr-rich $\alpha^{\prime}$ phase nucleated and grew within the $\gamma$-Fe grains and along grain boundaries. Note: the scale bar in the HAADF micrograph applies to all images in the figure.
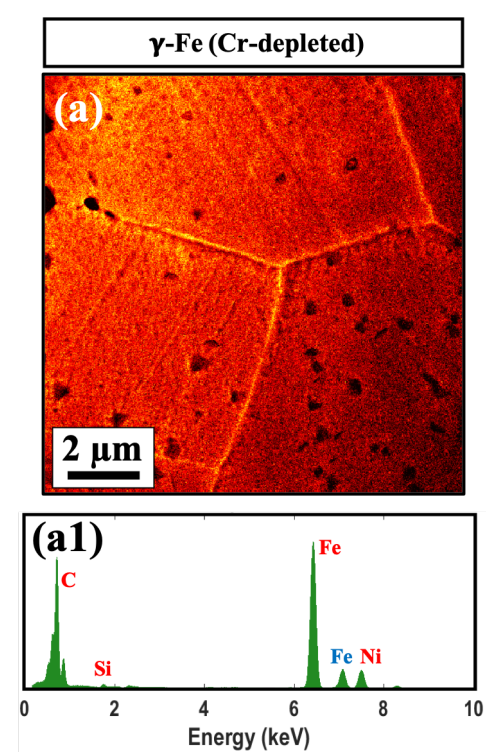
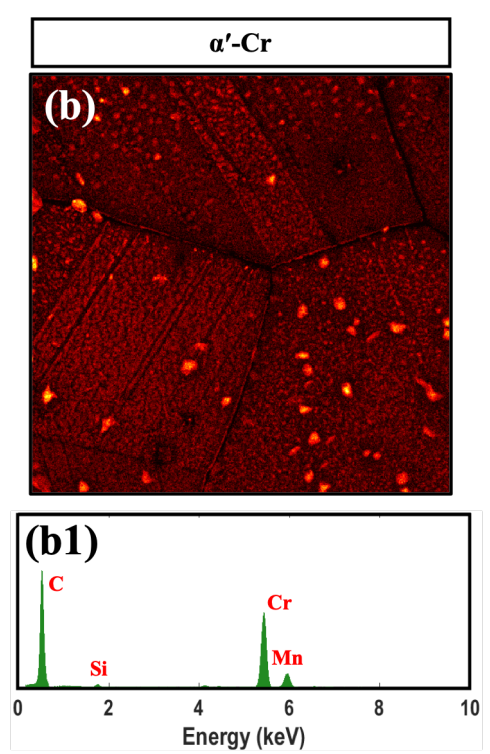
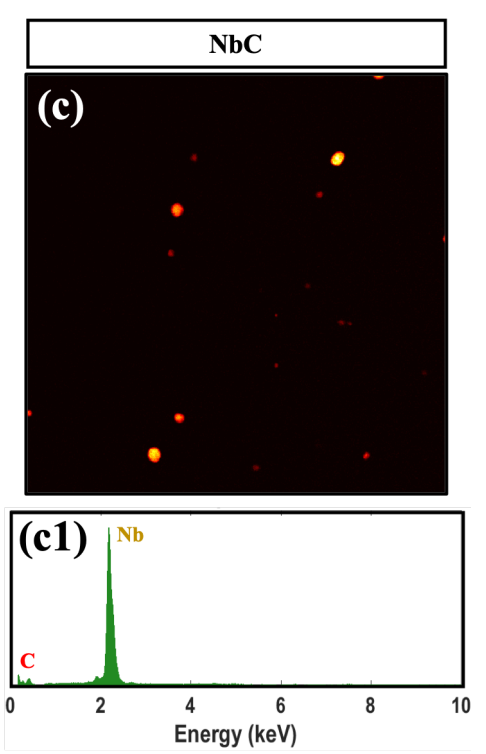

Figure 5: MVSA analysis corresponding to the STEM-EDX maps from figure 4 The spectral images and their correspondent EDX spectra are shown in: (a) and (a1) the $\gamma$-Fe phase depleted in Cr; (b) and (b1) the $\alpha^{\prime}$ phase; and (c) and (c1) the pre-existing $\mathrm{NbC}$. Note: the scale marker in (a) also applies to (b-c). 


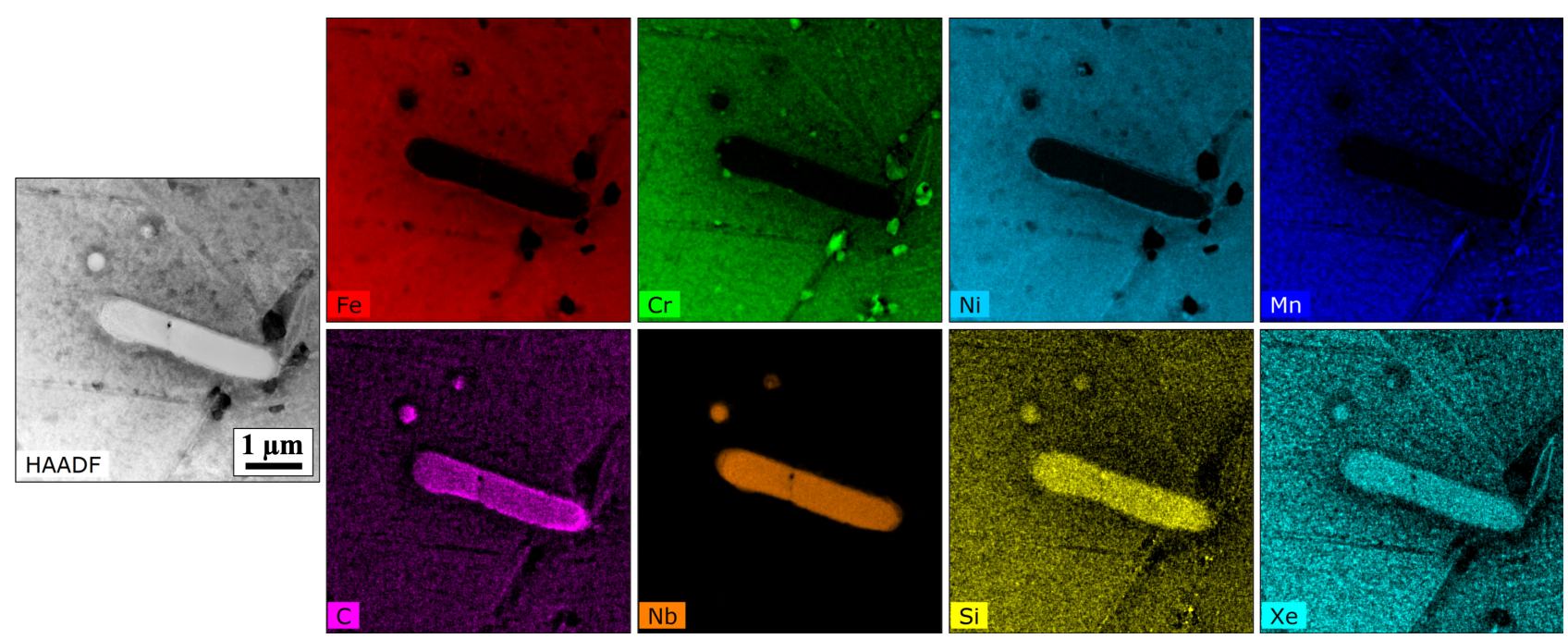

Figure 6: Low magnification STEM-EDX maps obtained from the AISI-348 steel irradiated up to $1.3 \times 10^{17}$ ions $\cdot \mathrm{cm}^{-2}$ (46 dpa) at $1073 \mathrm{~K}$ with $30 \mathrm{keV} \mathrm{Xe}$ ions showing that the regions around pre-existing (long) $\mathrm{NbC}$ are also sites for the $\alpha^{\prime}$ phase nucleation and growth. Note: the scale bar in the HAADF micrograph applies to all images in the figure.
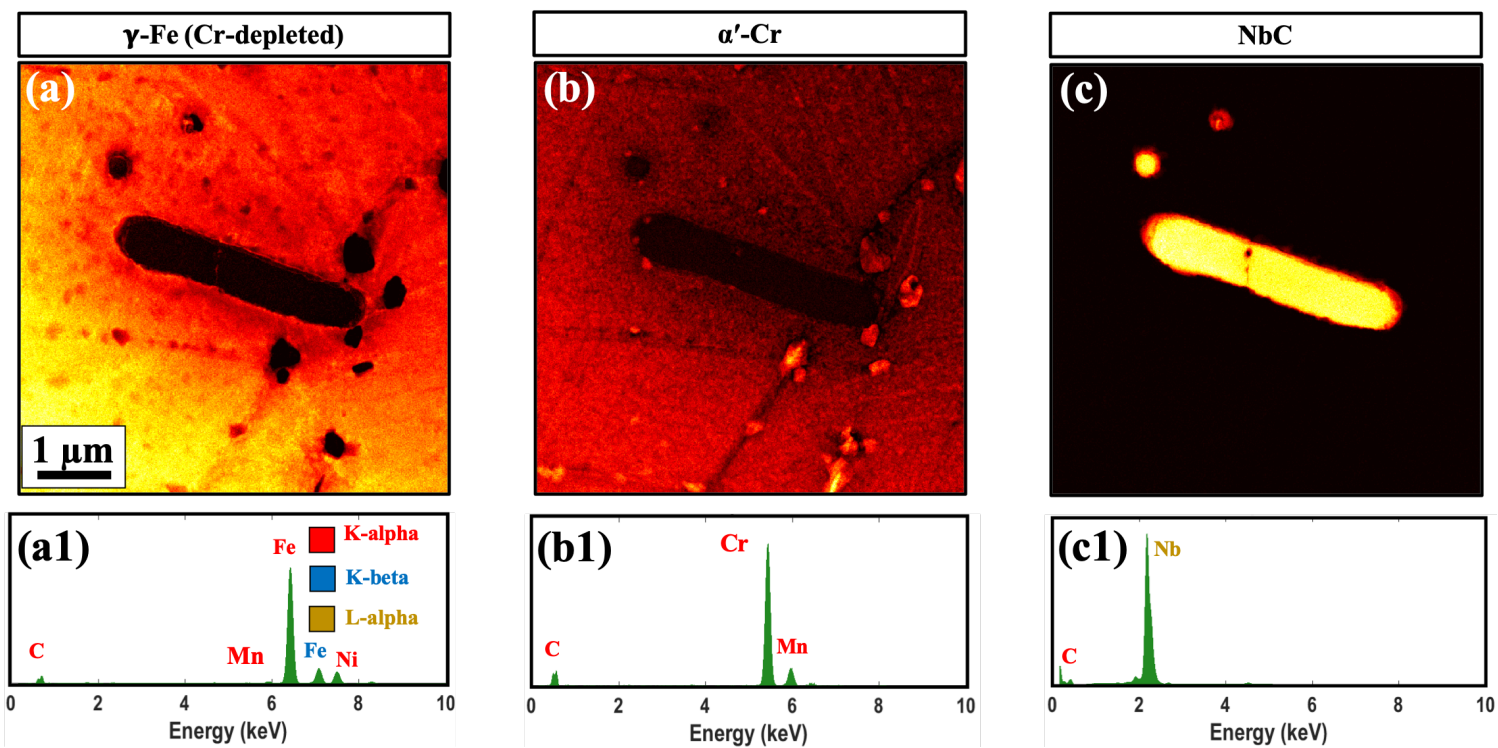

Figure 7: MVSA analysis corresponding to the STEM-EDX maps from figure 6 The spectral images and their correspondent EDX spectra are shown in: (a) and (a1) the $\gamma$-Fe phase depleted in Cr; (b) and (b1) the $\alpha^{\prime}$ phase; (c) and (c1) the pre-existing NbC. Note: the scale marker in (a) also applies to (b-c). 

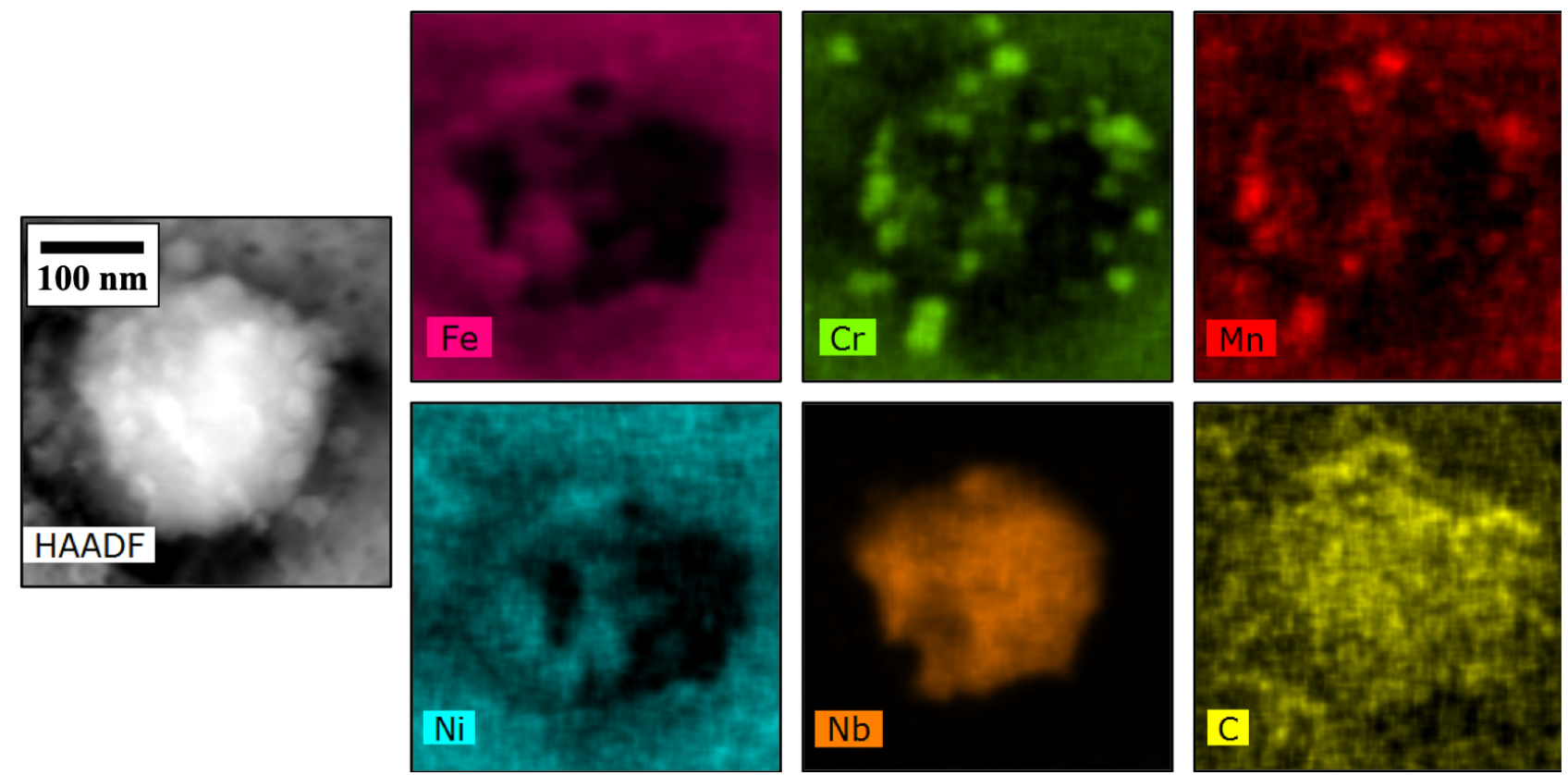

Figure 8: High-magnification STEM-EDX maps obtained from the AISI-348 steel irradiated up to $1.3 \times 10^{17}$ ions $\cdot \mathrm{cm}^{-2}$ (46 dpa) at $1073 \mathrm{~K}$ with $30 \mathrm{keV} \mathrm{Xe}$ ions revealing the presence of $\mathrm{M}_{23} \mathrm{C}_{6}$ nano-precipitates around a pre-existing $\mathrm{NbC}$. Note: the scale bar in the HAADF micrograph applies to all images in the figure.
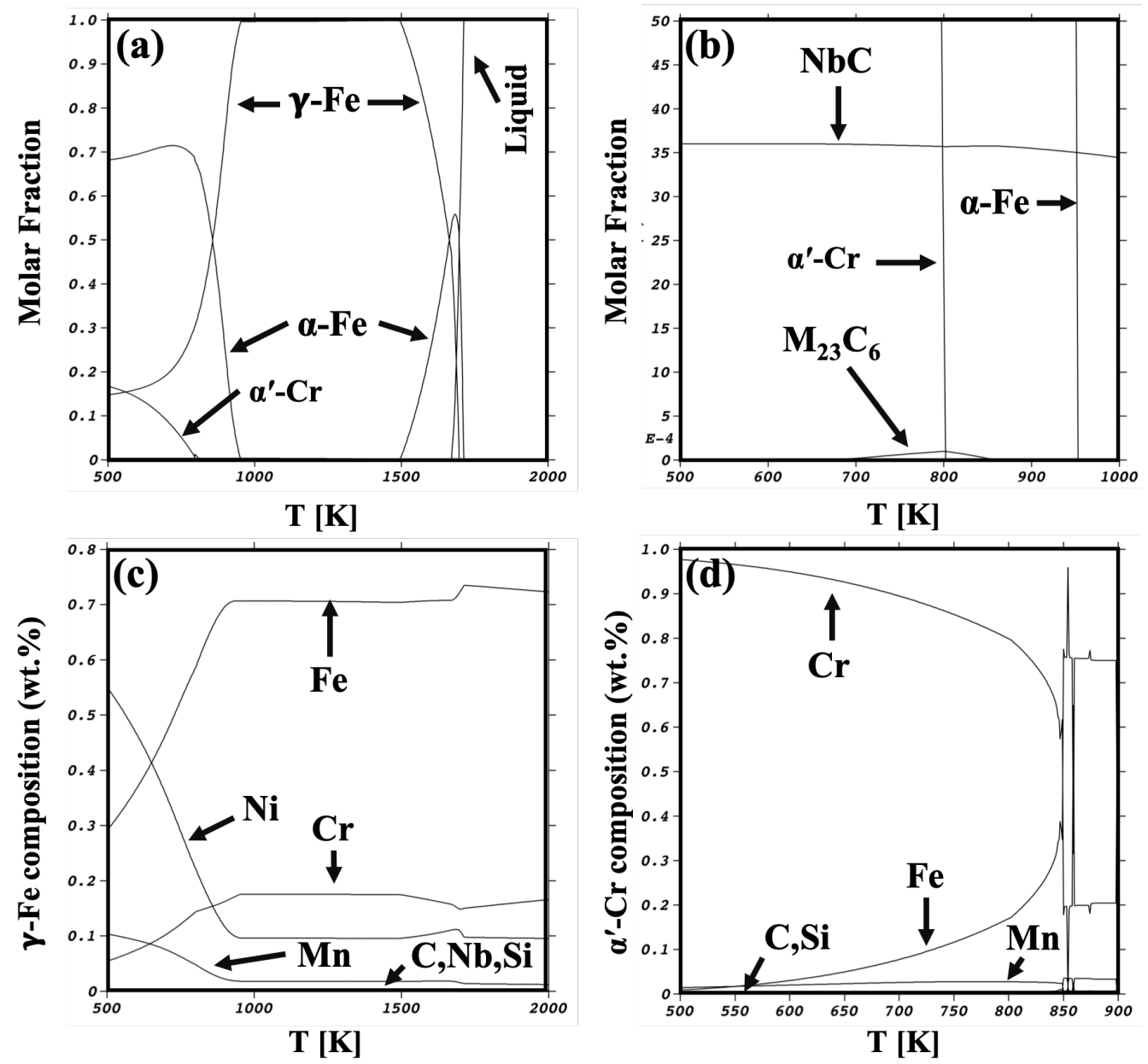

Figure 9: Equilibrium phase diagrams for the AISI-348 calculated with Thermo-Calc. The diagram (a) shows the molar fraction of phases present within the temperature range from 500 to $2000 \mathrm{~K}$ and (b) is a zoomed-region from the bottom part of the diagram (a), showing the $\mathrm{Nb}(\mathrm{C}, \mathrm{N})$ and $\mathrm{M}_{23} \mathrm{C}_{6}$ precipitates as minor phases. The elemental composition of the $\gamma$-Fe and the Cr-rich $\alpha^{\prime}$ phases are exhibited in (c) and (d) respectively. 
where it is found in equilibrium with $\gamma$-Fe and $\alpha$-Fe, as well as other minority phases. This is better appreciated when the scale is enlarged as shown in figure 9(b). It is observed that $\mathrm{NbC}$ and $\mathrm{M}_{23} \mathrm{C}_{6}$ are predicted as stable phases in the range between 700 to $850 \mathrm{~K}$. The compositions of the $\gamma$-Fe and of the $\alpha^{\prime}-\mathrm{Cr}$ are exhibited in the figures 9(c) and 9(d), respectively. In the figure 9(b), and in the corresponding enlarged scale detail from 9 (d) it is possible to observe the depletion of $\mathrm{Cr}$ in $\gamma$-Fe and the depletion of $\mathrm{Fe}$ in $\alpha^{\prime}-\mathrm{Cr}$ as the temperature is decreased. The composition of the $\gamma$-Fe, figure9 9 c), becomes significantly enriched in $\mathrm{Ni}$ at low temperatures

\section{Discussion}

\subsection{The decomposition of the $\gamma-F e$ and the formation of the Cr-rich $\alpha$ ' under in situ TEM heavy ion irradiation}

It is well-known that the diffusion of solute atoms in a multicomponent alloy [74], such as a stainless steel, occurs by the exchange of atoms with point defects. During irradiation, excess of Frenkel pairs (i.e. vacancies and interstitials), as introduced by the displacive collision, increases the diffusion rate in metals and may also open new pathways which are not available when only thermal diffusion takes place [75-78]. Although the concentration of defects is strongly reduced at higher temperatures due to their recombination, the heavy ion irradiation generates a large number of point defects per ion collision that reaches supersaturated levels.

In austenitic stainless steels, thermal treatments can promote the nucleation of new phases and precipitation, either in equilibrium or not, due to thermal solute segregation [11]. But the radiationinduced segregation phenomenon observed in this present work differs from annealing with respect to the population of generated point defects: RIS is a quasi-steady-state trade-off between solute diffusion enhanced by the particle irradiation due to the generation of a surplus of point defects (i.e. greater than thermal equilibrium) [28, 37]. The coupling between irradiation-enhanced solute diffusion and radiation-induced lattice defects mechanisms have resulted, to date, in two principal physical effects behind the RIS phenomenon [79]: (i) interstitial-solute (I-S) dragging effects which causes migration of alloying elements and enrichment at sinks and (ii) vacancy-inverse Kirkendall effect (V-IK) mediated by a vacancy flux (introduced by external forces) and that causes depletion of atomic species by changing the interdiffusion coefficients [80]. RIS also differs from thermal annealing in respect to the time-scale and composition of new phases and precipitates that may form under irradiation: it is faster than annealing and formed phases may exhibit inhomogeneities in composition.

In this work, using in situ TEM with heavy ion irradiation at $1073 \mathrm{~K}$, it is reported that the $\gamma$-Fe phase started to decompose and form Cr-rich zones at a fluence of around $7.8 \times 10^{15}$ ions $\cdot \mathrm{cm}^{-2}(3 \mathrm{dpa})$. Upon increasing the dose, more Cr-rich zones started to nucleate and grow and the AISI-348, initially a single-phase alloy, exhibits a microstructure of two major phases. Post-irradiation characterisation in a TEM indicates that the new phase is of BCC crystal structure, confirmed by SAED patterns indexed with data available in the crystallography literature [64]. The STEM-EDX mapping and the MVSA have also indicated that these zones are not pure $\mathrm{Cr}$, but it also has $\mathrm{Mn}, \mathrm{Si}$ and $\mathrm{C}$ as minor elements which also agree with the calculated composition presented in 9 (d). 
The enhanced diffusion and segregation of solute atoms as a direct consequence of the heavy ion irradiation have allowed this BCC Cr-rich phase to form and grow within the $\gamma$-Fe matrix. By the continuous introduction of vacancies and interstitials at high levels promoted by heavy ion collisions, the formation of such new phases under irradiation is favoured due to lowering the Gibbs free energy of the system by eliminating concentration gradients of solute atoms that are knocked-out from their lattice positions. The nucleation of small embryos at around 3 dpa may be also related with the occurrence of Xe bubbles within the microstructure that creates surfaces for heterogeneous nucleation [36]. Additionally, the fast kinetics of formation of these Cr-rich zones observed in the present results can be justified not only by the enhanced bulk diffusivity due to the excess vacancies produced by irradiation, but also by the role of the free surfaces in electron-transparent samples which act both by offering sites for heterogeneous nucleation of the new phase and by contributing to overall diffusion via surface diffusion.

The incompatibility in the temperatures does not invalidate the observation of $\alpha^{\prime}$ phase in the irradiation experiments, as the calculations refer to an equilibrium state whilst the sample is evidently out of equilibrium. In addition, the calculations are based on polynomial expansions of the free energies of the phases, obtained by fitting to equilibrium properties at higher temperatures and/or in different systems [71]. The results of the present calculations are, therefore, based on the extrapolation of these functions beyond the composition, temperature and pressure ranges in which their parameters were fitted. In fact, it is surprising that the calculations reproduce qualitatively the irradiated microstructures. This shows that instead of bringing the system to a metastable state, as usually assumed, irradiation here is leading the system to decompose from a metastable state ( $\gamma$-Fe phase) into a state closer to the true equilibrium state at lower temperatures. Naturally, the full equilibrium is not attained since energy is being continuously deposited in the system, and also the low temperature and time involved are insufficient to allow complete redistribution of elements, but it is remarkable that the equilibrium phases $\left(\alpha^{\prime}\right.$ and $\mathrm{M}_{23} \mathrm{C}_{6}$ ) are obtained and that the phase compositions are consistent with what is predicted from the calculations.

To understand the relevance of this observation, we may draw a parallel to another degradation phenomenon in engineering: creep. The resistance a material offers to deform under the action of stresses at high temperatures is significantly impaired if this material undergoes a phase transformation during the process [81]. Alloy design for high temperature therefore requires thermodynamically stable microstructures. The observation of the irradiation damage in the present experiments could be a manifestation of the same criterion. A thermodynamically more stable $\gamma$-Fe (for example, increasing the alloy content of nickel or manganese) could provide a better irradiation resistance to the material.

MVSA carried out from the low-magnification STEM-EDX mapping, presented in figure 5, reveals that the radiation-induced $\alpha^{\prime}$ has preferentially $\mathrm{Cr}, \mathrm{Mn}, \mathrm{Si}$ and $\mathrm{C}$ in solution, as evidenced in the spectrum in figure 6(d), but the Fe and Ni maps in figure 4 confirm that it contains these elements, but at reduced quantities. This fact is in agreement with the $\alpha^{\prime}$ composition estimated by the calculations with Thermo-Calc, figure 9(d): the $\alpha^{\prime}$ is distinguishable from ferrite by the differences in $\mathrm{Cr}$ composition. Ferrite, which also possesses BCC structure, was not observed to form in the experimental 
conditions of this work.

\subsection{The impact of the $\alpha^{\prime}$ formation in the steel and the role of $N b$-stabilisation}

Using a simplified disperse barrier hardening (DBH) model, Field et al. [82] indicated that the formation of the $\mathrm{Cr}$-rich $\mathrm{BCC} \alpha^{\prime}$ in $\mathrm{FeCrAl}$ steels promotes hardening, although its contribution was estimated to be one order of magnitude smaller than the hardening by dislocations. The hardening effect of $\alpha^{\prime}$ in the so-called "750 K embrittlement" [83] is attributed to the fine microstructure obtained by spinodal decomposition, this would be hardly reproduced in the present microstructures, with coarser particles. Edmondson et al. [53] commented on the absence of studies in the effects of the $\alpha^{\prime}$ formation in both $\mathrm{FeCr}$ and $\mathrm{FeCrAl}$ alloys. It is evident that the formation of a secondary phase within the $\gamma$-Fe matrix has deleterious effects in the structural integrity of the steel. Whether this effect may compromise the applicability of the AISI-348 within the extremes of nuclear environments, it is a subject to further investigations.

Furthermore, the STEM-EDX mapping has also revealed that the $\mathrm{NbC}$ is an active sink for $\mathrm{C}, \mathrm{Si}$ and $\mathrm{Xe}$. In regions around the $\mathrm{NbC}$ nanoparticles, figures 6 and 7 , the $\mathrm{Cr}$-rich $\alpha^{\prime}$ is more depleted in $\mathrm{Ni}$ and $\mathrm{Fe}$ than when the radiation-induced phase is formed far from the carbide sites. A slight $\mathrm{Ni}$ uptake can be noticed at the $\mathrm{NbC}$ boundaries.

The addition of $\mathrm{Nb}$ into the AISI-348 is known to have three major effects in austenitic steels [14, 84, 85]: (i) suppress the $\gamma$-Fe grain coarsening during annealing, (ii) avoid the $\gamma$-Fe phase recrystallisation prior to the $\alpha / \gamma$ transformation by means of strain induced precipitation of $\mathrm{NbC}$ and (iii) precipitation hardening due to the formation of $\mathrm{NbC}$. This work experimentally shows that the presence of $\mathrm{NbC}$ in the $\gamma$-Fe matrix does not inhibit the formation of the Cr-rich $\alpha^{\prime}$ neither the $\mathrm{M}_{23} \mathrm{C}_{6}$ nano-precipitates under heavy ion irradiation, although it exhibits that the $\mathrm{Fe}$ and Ni contents are more depleted within the $\alpha^{\prime}$ closer to the $\mathrm{NbC}$ when compared to the phases formed within the $\gamma$-Fe grains without the $\mathrm{Nb}$ precipitates. In this way, it is confirmed that the addition of $\mathrm{Nb}$ for the stabilisation of the AISI 348 was not sufficient to prevent precipitation under the irradiation conditions investigated in this work. The possibility of locally enhancing the $\mathrm{C}$ content within the austenite phase by displacing $\mathrm{C}$ atoms from the $\mathrm{NbC}$ nanoparticles as a result of the energetic particle collisions is also believed to accelerate the kinetics of precipitation.

The results in this manuscript indicate that introduction of point defects in excess as a result of atomic collisions with the austenitic stainless steel destabilises the $\gamma$-Fe matrix phase promoting nucleation of secondary phases ( $\alpha$ ' and $\tau$-carbides) which are found in the calculated thermodynamic equilibrium of the steel in opposition to previous reports which often indicate that the energetic particle irradiation induces a wide variety of microstructural and microchemical alterations resulting that irradiation often produces an alloy that cannot be found in equilibrium diagrams [26]. In this way, it was experimentally observed and characterised that the heavy ion irradiation - under the studied conditions - promotes the nucleation of such phases as the $\alpha \prime$ and $\tau$-carbides, but somehow suppress the formation of possible non-equilibrium phases such as $\gamma^{\prime}$ and the G phase already reported to occur in similar alloys (i.e. AISI-316). Therefore, the physical phenomenon of radiation damage in austenitic stainless steels encounters interesting analogies with several other mechanisms that can induce degradation in materials such as creep. 


\section{Conclusions}

In the present work we report on the real-time decomposition of the $\gamma$-Fe phase into $\alpha^{\prime}$ (a Cr-rich BCC phase) in a Nb-stabilised commercial austenitic stainless steel (AISI-348) with in situ TEM heavy ion irradiation. The major outcomes of this work can be summarised as follows:

- The nucleation of the Cr-rich $\alpha^{\prime}$ phase started at around $7.8 \times 10^{15}$ ions $\cdot \mathrm{cm}^{-2}$ (3 dpa). Their sizes were between 1 to $2 \mu \mathrm{m}$ after $2.8 \times 10^{16}$ ions $\cdot \mathrm{cm}^{-2}$ (10 dpa) and no significant growth was observed at higher doses.

- Selected-area diffraction pattern indexed with data available in literature have indicated that the new phase formed during the irradiation was of BCC crystal structure.

- The combination of STEM-EDX mapping and MVSA have indicated the segregation of alloying elements throughout the $\gamma$-Fe played a major role in the formation of the Cr-rich phase. Additionally, it shows that the new phase is not pure $\mathrm{Cr}$, but also shows $\mathrm{Si}, \mathrm{C}, \mathrm{Ni}$ and $\mathrm{Mn}$ in smaller quantities.

- $\mathrm{M}_{23} \mathrm{C}_{6}$ nano-precipitates were also observed to form during the experiments of both $\gamma$-Fe and $\alpha^{\prime}$. STEM-EDX at high magnifications showed that such nano-precipitates are highly enriched in $\mathrm{Cr}, \mathrm{Mn}$ and $\mathrm{C}$ and also nucleate and grow around pre-existing $\mathrm{NbC}$ particles within the $\gamma$-Fe phase.

- The addition of $\mathrm{Nb}$ in solid solution aiming at enhancing the corrosion resistance of the AISI348 by promoting nucleation of $\mathrm{NbC}$ via stabilizing heat treatment was not found to be sufficient to prevent the radiation-induced precipitation of $\mathrm{M}_{23} \mathrm{C}_{6}$ nor the Cr-rich $\alpha^{\prime}$ phase under the irradiation conditions studied in this work.

- Equilibrium thermodynamic calculations indicates that the Cr-rich phase formed during the irradiation is the BCC Cr-rich $\alpha^{\prime}$. These calculations indicate that the heavy ion irradiation could be assisting the AISI-348 towards thermodynamic equilibrium from an initial metastable condition ( $\gamma$-Fe phase), although the calculated equilibrium state is expected to exist at lower temperatures when compared with the irradiation temperature reported in this work. This is due to the irradiation-induced destabilisation of the $\gamma$-Fe phase.

The Fe-rich $\alpha$-phase was not detected within the experiments reported in this work, although it is present in the calculated equilibrium diagrams for the AISI-348. It must be remembered that the presence of this phase in the irradiation experiments is not necessary, since the irradiated alloy does not reach the complete thermodynamic equilibrium. Therefore, further works are needed to identify the formation of either Cr-rich $\alpha^{\prime}$-phase and the Fe-rich $\alpha$-phase during heat treatments and/or different irradiation conditions in order to evaluate the conditions for their formation. An evaluation of the mechanical properties of the AISI-348 after irradiation is also needed in order to assess its mechanical performance when such precipitation phases are formed. The latter is of paramount importance 
within the context of austenitic stainless steels as candidate materials for nuclear fuel cladding in nuclear reactors. Future works could also address the formation of secondary phases as per induced by the irradiation in the AISI-348 steel in its bulk form.

\section{Data Availability}

The raw and processed data required to reproduce these findings are available to download in the link doi:10.17632/tvzc8f9w5z.3 permanently stored at the Mendeley Data repository.

\section{Acknowledgements}

The authors are grateful to the European Research Council (ERC) excellent science grant "TRANSDESIGN" through the Horizon 2020 programme under contract 757961 and by the financial support from the Austrian Research Promotion Agency (FFG) in the project 3DnanoAnalytics (FFG-No 858040). All the authors are grateful to the Engineering and Physical Sciences Research Council (EPRSC) for funding MIAMI facilities under the grants EP/E017266/1 and EP/M028283/1. MAT acknowledges previous support from ASTRO - a United States Department of Energy workforce development program implemented at Oak Ridge National Laboratory through the Oak Ridge Institute for Science and Education under contract number DE-AC05-06OR23100. CGS acknowledges partial financial support by the São Paulo State Research Funding Agency (FAPESP, São Paulo, Brazil), under grant no. 2016/25248-3 and by the Brazilian National Research Council (CNPq, Brasília, Brazil) under the grant no. 312424/2013-2. MAT and CGS thank Dr. Nathanael W.S. Morais (USP) for crosschecking the AISI-348 elemental composition analysis presented in this paper. MAT and VMV would like to thank and to Prof. U. Bangert (UL) and Dr. A. Harvey (UL) by previous support with electron microscopy. The authors thank Univ.-Prof. Ernst Kozeschnik (TU Wien) for his deep appreciation of this present work and for the useful discussions on the thermodynamics of austenitic stainless steels. MAT would like to thank Univ.-Prof. Helmut Antrekowitsch (MU Leoben), Univ.-Prof. Peter J. Uggowitzer (MU Leoben/ETHz), Ms. Claudia Hackl (MU Leoben) and all the Nichteisenmetallurgie.at team (MU Leoben) for all the provided support and warm reception in Austria.

\section{References}

[1] G. S. Was, S. Taller, Z. Jiao, A. M. Monterrosa, D. Woodley, D. Jennings, T. Kubley, F. Naab, O. Toader, E. Uberseder, Resolution of the carbon contamination problem in ion irradiation experiments, Nuclear Instruments and Methods in Physics Research, Section B: Beam Interactions with Materials and Atoms 412 (2017) 58-65. doi:10.1016/j.nimb.2017.08.039

URL https://www.sciencedirect.com/science/article/pii/S0168583X17308315

[2] S. J. Zinkle, P. J. Maziasz, R. E. Stoller, Dose dependence of the microstructural evolution in neutron-irradiated austenitic stainless steel, Journal of Nuclear Materials 206 (2-3) (1993) 266-286. doi:10.1016/0022-3115(93) 90128-L

URL http://www.sciencedirect.com/science/article/pii/002231159390128L

[3] S. J. Zinkle, G. S. Was, Materials challenges in nuclear energy, Acta Materialia 61 (3) (2013) 735-758. doi : http: //dx.doi.org/10.1016/j.actamat.2012.11.004 URL http://www.sciencedirect.com/science/article/pii/S1359645412007987 
[4] P. Hosemann, Studying radiation damage in structural materials by using ion accelerators, in: Reviews Of Accelerator Science And Technology: Volume 4: Accelerator Applications in Industry and the Environment, World Scientific, 2011, pp. 161-182.

[5] D. Olander, Nuclear fuels-present and future, Journal of Nuclear Materials 389 (1) (2009) 1-22.

[6] T. Gräning, M. Rieth, J. Hoffmann, S. Seils, P. D. Edmondson, A. Möslang, Microstructural investigation of an extruded austenitic oxide dispersion strengthened steel containing a carbon-containing process control agent, Journal of Nuclear Materials 516 (2019) 335-346.

[7] M. T. Simnad, A brief history of power reactor fuels, Journal of Nuclear Materials 100 (1-3) (1981) 93-107. doi: 10.1016/0022-3115(81)90524-9.

URL http://linkinghub.elsevier.com/retrieve/pii/0022311581905249

[8] G. E. Lucas, The evolution of mechanical property change in irradiated austenitic stainless steels, Journal of Nuclear Materials 206 (2-3) (1993) 287-305. doi :10.1016/0022-3115(93)90129-M. URL http://www.sciencedirect.com/science/article/pii/002231159390129M

[9] A. Tavassoli, Assessment of austenitic stainless steels, Fusion Engineering and Design 29 (1995) 371-390.

[10] S. Şahin, M. Übeyli, A review on the potential use of austenitic stainless steels in nuclear fusion reactors, Journal of fusion energy 27 (4) (2008) 271-277.

[11] H. Bhadeshia, R. Honeycombe, Steels Microstructure and Properties, Butterworth-Heinemann, 2017.

[12] T. Sourmail, Precipitation in creep resistant austenitic stainless steels Materials Science and Technology 17 (1) (2001) 1-14. doi:10.1179/026708301101508972.

URL http: //www . tandfonline.com/doi/full/10.1179/026708301101508972

[13] M. Schwind, J. Källqvist, J.-O. Nilsson, J. Ågren, H.-O. Andrén, $\sigma$-phase precipitation in stabilized austenitic stainless steels, Acta Materialia 48 (10) (2000) 2473-2481.

[14] J. Erneman, M. Schwind, P. Liu, J.-O. Nilsson, H.-O. Andren, J. Ågren, Precipitation reactions caused by nitrogen uptake during service at high temperatures of a niobium stabilised austenitic stainless steel, Acta Materialia 52 (14) (2004) 4337-4350.

[15] K. Chandra, V. Kain, V. Bhutani, V. Raja, R. Tewari, G. Dey, J. Chakravartty, Low temperature thermal aging of austenitic stainless steel welds: kinetics and effects on mechanical properties, Materials Science and Engineering: A 534 (2012) 163-175.

[16] T. Masumura, N. Nakada, T. Tsuchiyama, S. Takaki, T. Koyano, K. Adachi, The difference in thermal and mechanical stabilities of austenite between carbon-and nitrogen-added metastable austenitic stainless steels, Acta Materialia 84 (2015) 330-338.

[17] M. M. Timm, Í. M. Oyarzabal, F. Tatsch, L. Amaral, P. F. Fichtner, Au and ag ion irradiation effects on the carbide precipitation and ar bubble formation in solubilized AISI 316L alloys, Nuclear Instruments and Methods in Physics Research Section B: Beam Interactions with Materials and Atoms.

[18] Í. M. Oyarzabal, M. d. M. Timm, W. M. Pasini, F. S. de Oliveira, F. Tatsch, L. Amaral, P. F. Fichtner, Influence of ar implantation on the precipitation in au ion irradiated AISI 316L solution annealed alloy, MRS Advances 3 (31) (2018) 1799-1805.

[19] Z. Jiao, G. Was, Novel features of radiation-induced segregation and radiation-induced precipitation in austenitic stainless steels, Acta Materialia 59 (3) (2011) 1220-1238.

[20] O. Klok, K. Lambrinou, S. Gavrilov, I. De Graeve, Influence of oxygen concentration on the initiation of dissolution corrosion on 3161 austenitic stainless steel at 450 c, in: 25th International Conference on Nuclear Engineering, American Society of Mechanical Engineers, 2017, p. V003T02A047.

[21] C. Barcellini, R. Harrison, S. Dumbill, S. Donnelly, E. Jimenez-Melero, Evolution of radiation-induced lattice defects in 20/25 nb-stabilised austenitic stainless steel during in-situ proton irradiation, Journal of Nuclear Materials 514 (2019) 90-100.

[22] C. Barcellini, R. Harrison, S. Dumbill, S. Donnelly, E. Jimenez-Melero, Local chemical instabilities in 20cr25ni nbstabilised austenitic stainless steel induced by proton irradiation, Journal of Nuclear Materials 518 (2019) 95-107.

[23] B. Sencer, G. Bond, M. Hamilton, F. Garner, S. Maloy, W. Sommer, Microstructural origins of radiation-induced changes in mechanical properties of 3161 and 3041 austenitic stainless steels irradiated with mixed spectra of 
high-energy protons and spallation neutrons, Journal of nuclear materials 296 (1-3) (2001) 112-118.

[24] B. H. Sencer, S. A. Maloy, M. L. Hamilton, F. A. Garner, Microstructural evolution of both as-irradiated and subsequently deformed microstructures of 3161 stainless steel irradiated at 30-160 c at lansce, Journal of nuclear materials 345 (2-3) (2005) 136-145.

[25] J. Wang, Z. Li, D. Wang, S. Qiu, F. Ernst, Thermal stability of low-temperature-carburized austenitic stainless steel, Acta Materialia 128 (2017) 235-240.

[26] F. Garner, Radiation damage in austenitic steels, in: Comprehensive Nuclear Materials, Vol. 4, Elsevier Oxford, 2012, pp. 33-95.

[27] J.-H. Shim, E. Povoden-Karadeniz, E. Kozeschnik, B. D. Wirth, Modeling precipitation thermodynamics and kinetics in type 316 austenitic stainless steels with varying composition as an initial step toward predicting phase stability during irradiation, Journal of Nuclear Materials 462 (2015) 250 - 257. doi:https://doi.org/10.1016/j. jnucmat.2015.04.013. URL http://www.sciencedirect.com/science/article/pii/S0022311515002159

[28] P. J. Maziasz, Formation and stability of radiation-induced phases in neutron-irradiated austenitic and ferritic steels, Journal of Nuclear Materials 169 (C) (1989) 95-115. doi:10.1016/0022-3115(89) 90525-4.

[29] D. R. Arkell, P. C. L. Pfeil, Transmission electron microscopical examination of irradiated austenitic steel tensile specimens, Journal of Nuclear Materials 12 (2) (1964) 145-152. doi:http://dx.doi.org/10.1016/ 0022-3115(64)90134-5

URL http://orproxy.lib.utk.edu:2053/science/article/pii/0022311564901345http://www. sciencedirect.com/science/article/pii/0022311564901345

[30] T. R. Anthony, Solute segregation and stresses generated around growing voids in metals, in: J.W. Cobertt and L.C. Ianniello (Ed.), Radiation-induced voids in metals, Vol. 15, USAEC CONF-710601, 1971, pp. 630-646.

URL http://www.dtic.mil/docs/citations/AD0732507

[31] P. Okamoto, S. Harkness, J. Laidler, Solute segregation to voids during electron irradiation, Trans. Amer. Nucl. Soc 16 p. 70 (1973) 1317-1330. doi:doi.org/10.1016/0001-6160(78)90147-5

[32] P. R. Okamoto, H. Wiedersich, Segregation of alloying elements to free surfaces during irradiation, Journal of Nuclear Materials 53 (C) (1974) 336-345. doi:10.1016/0022-3115(74)90267-0.

URL http://www.sciencedirect.com/science/article/pii/0022311574902670

[33] V. Sethi, P. Okamoto, Radiation-induced segregation in complex alloys, Tech. rep., Argonne National Lab., IL (USA) (1980).

[34] P. R. Okamoto, L. E. Rehn, Radiation-induced segregation in binary and ternary alloys, Journal of Nuclear Materials 83 (1) (1979) 2-23. doi:10.1016/0022-3115(79)90587-7

[35] P. J. Maziasz, C. J. McHargue, Microstructural evolution in annealed austenitic steels during neutron irradiation. International Materials Reviews 32 (1) (1987) 190-219. doi:10.1179/095066087790150331.

URL http://www.tandfonline.com/doi/full/10.1179/095066087790150331

[36] P. Maziasz, P.J., Effects of helium content of microstructural development in Type 316 stainless steel under neutron irradiation, Tech. rep., Oak Ridge National Laboratory (ORNL), Oak Ridge, TN (United States) (nov 1985). doi : 10.2172/6441891

URL http://www.osti.gov/servlets/purl/6441891-1MVi1A/

[37] T. R. Allen, J. I. Cole, J. Gan, G. S. Was, R. Dropek, E. A. Kenik, Swelling and radiation-induced segregation in austentic alloys, Journal of Nuclear Materials 342 (1-3) (2005) 90-100. doi : 10.1016/j · jnucmat.2005.02.008

[38] Z. Jiao, G. S. Was, Novel features of radiation-induced segregation and radiation-induced precipitation in austenitic stainless steels. Acta Materialia 59 (3) (2011) 1220-1238. doi:10.1016/j . actamat.2010.10.055 URL http://www.sciencedirect.com/science/article/pii/S1359645410007299

[39] S. Jin, L. Guo, F. Luo, Z. Yao, S. Ma, R. Tang, Ion irradiation-induced precipitation of Cr 23C 6 at dislocation loops in austenitic steel, Scripta Materialia 68 (2) (2013) 138-141. doi:10.1016/j.scriptamat.2012.10.002 URL http://dx.doi.org/10.1016/j.scriptamat.2012.10.002

[40] M. A. Tunes, C. G. Schön, G. Greaves, Radiation-induced precipitation with concurrent bubbles formation in an austenitic stainless steel (AISI-348), Materialia (2019) 100408. 
[41] B. Weiss, R. Stickler, Phase instabilities during high temperature exposure of 316 austenitic stainless steel, Metallurgical Transactions 3 (4) (1972) 851-866. doi : 10.1007/BF02647659.

URL http://link.springer.com/10.1007/BF02647659

[42] J. E. Spruiell, J. A. Scott, C. S. Ary, R. L. Hardin, Microstructural stability of thermal-mechanically pretreated type 316 austenitic stainless steel, Metallurgical Transactions 4 (6) (1973) 1533-1544. doi:10.1007/BF02668005. URL https://link.springer.com/article/10.1007/BF02668005

[43] E. Lee, P. Maziasz, A. Rowcliffe, Structure and composition of phases occurring in austenitic stainless steels in thermal and irradiation environments, in: Symposium on irradiation phase stability, Pittsburgh, PA, USA, 5 Oct 1980, 1980, pp. 191-218.

URL https://www .osti.gov/scitech/biblio/5889791

[44] T. M. Williams, J. M. Titchmarsh, D. R. Arkell, Void-swelling and precipitation in a neutron-irradiated, niobiumstabilised austenitic stainless steel, Journal of Nuclear Materials 107 (2-3) (1982) 222-244. doi:10.1016/ 0022-3115(82)90423-8

URL http://www.sciencedirect.com/science/article/pii/0022311582904238

[45] J. M. Titchmarsh, S. Dumbill, Multivariate statistical analysis of STEM-EDX data from radiation-induced sensitization in stainless steel, Journal of Microscopy 188 (03) (1997) 224-236. doi:10.1046/j.1365-2818.1997. 2610817.x. URL http://doi.wiley.com/10.1046/j.1365-2818.1997.2610817.x

[46] T. Williams, Precipitation in Irradiated and Unirradiated Austenitic Steels, in: Effects of Radiation on Materials, ASTM International, 100 Barr Harbor Drive, PO Box C700, West Conshohocken, PA 19428-2959, 1982, pp. 166166-20. doi:10.1520/STP34345S

URL http://www .astm.org/doiLink.cgi?STP34345S

[47] C. A. English, B. L. Eyre, Heavy-ion damage in Alpha-Fe, Nature 260 (1976) 619-21. doi:10.1038/260170a0 URL http://www.ncbi.nlm.nih.gov/pubmed/1264226

[48] F. Garner, L. Greenwood, R. Mizia, C. Tyler, Assessment of xm-19 as a substitute for aisi 348 in atr service, Tech. rep., Idaho National Laboratory (INL) (2007).

[49] J. E. Irvin, A. L. Bernent, Nature of Radiation Damage to Engineering Properties of Various Stainless Steel Alloys. in: Effects of Radiation on Structural Metals, ASTM International, 100 Barr Harbor Drive, PO Box C700, West Conshohocken, PA 19428-2959, 1967, pp. 278-278-50. doi:10.1520/STP41327S

URL http://www . astm.org/doiLink.cgi?STP41327S

[50] J. J. Holmes, R. E. Robbins, A. J. Lovell, Postirradiation Tensile Behavior of 300 Series Stainless Steels, in: Irradiation Effects in Structural Alloys for Thermal and Fast Reactors, ASTM International, 100 Barr Harbor Drive, PO Box C700, West Conshohocken, PA 19428-2959, 1969, pp. 371-371-19. doi:10.1520/STP41858S

URL http://www . astm.org/doiLink. cgi?STP41858S

[51] J. E. Irvin, A. L. Bement, R. G. Hoagland, The Combined Effects of Temperature and Irradiation on the Mechanical Properties of Austenitic Stainless Steels, in: Flow and Fracture of Metals and Alloys in Nuclear Environments, ASTM International, 100 Barr Harbor Drive, PO Box C700, West Conshohocken, PA 19428-2959, 1965, pp. 236236-15. doi:10.1520/STP43532S.

URL http://www. astm.org/doiLink.cgi?STP43532S

[52] M. Bachhav, G. Robert Odette, E. A. Marquis, $\alpha$-prime precipitation in neutron-irradiated Fe-Cr alloys, Scripta Materialia 74 (2014) 48-51. doi:10.1016/j.scriptamat.2013.10.001.

URL http://orproxy.lib.utk.edu:2053/science/article/pii/S1359646213004995

[53] P. D. Edmondson, S. A. Briggs, Y. Yamamoto, R. H. Howard, K. Sridharan, K. A. Terrani, K. G. Field, Irradiationenhanced $\alpha$-prime precipitation in model FeCrAl alloys, Scripta Materialia 116 (2016) 112-116. doi: 10.1016/j. scriptamat.2016.02.002

URL http://dx.doi.org/10.1016/j.scriptamat.2016.02.002

[54] R. Harrison, A. Carruthers, J. Hinks, M. Burke, S. Donnelly, Cascade size and dose rate effects on alpha-prime precipitation in ion-irradiated Fe14Cr alloy, Scripta Materialia 172 (2019) 33-37.

[55] W.-Y. Chen, Y. Miao, Y. Wu, C. A. Tomchik, K. Mo, J. Gan, M. A. Okuniewski, S. A. Maloy, J. F. Stubbins, Atom 
probe study of irradiation-enhanced $\alpha^{\prime}$ precipitation in neutron-irradiated fe-cr model alloys, Journal of Nuclear Materials 462 (2015) 242-249.

[56] K. G. Field, B. Eftink, C. Parish, T. Saleh, S. Maloy, Synergies between $\alpha$ ' and cavity formation in ht-9 following high dose neutron irradiation, Tech. Rep. ORNL/TM-2017/274, Oak Ridge National Laboratory (2017).

[57] S. A. Briggs, P. D. Edmondson, K. C. Littrell, Y. Yamamoto, R. H. Howard, C. R. Daily, K. A. Terrani, K. Sridharan, K. G. Field, A combined APT and SANS investigation of $\alpha$-prime phase precipitation in neutron-irradiated model FeCrAl alloys, Acta Materialia 129 (Supplement C) (2017) 217-228. doi:https://doi.org/10.1016/ j.actamat.2017.02.077. URL http://www.sciencedirect.com/science/article/pii/S1359645417301787

[58] E. Aydogan, J. S. Weaver, S. A. Maloy, O. El-Atwani, Y. Wang, N. A. Mara, Microstructure and mechanical properties of fecral alloys under heavy ion irradiations, Journal of Nuclear Materials 503 (2018) 250-262.

[59] K. G. Field, S. A. Briggs, K. Sridharan, R. H. Howard, Y. Yamamoto, Mechanical properties of neutron-irradiated model and commercial fecral alloys, Journal of Nuclear Materials 489 (2017) 118-128.

[60] J. Berling, T. Slot, Effect of Temperature and Strain Rate on Low-Cycle Fatigue Resistance of AISI 304, 316, and 348 Stainless Steels, in: Fatigue at High Temperature, ASTM International, 100 Barr Harbor Drive, PO Box C700, West Conshohocken, PA 19428-2959, 1969, pp. 3-3-28. doi:10.1520/STP33646S. URL http: //www . astm.org/doiLink.cgi?STP33646S

[61] F. B. Pickering, Physical metallurgy and the design of steels, Applied Science Publishers, 1978.

[62] C. Solenthaler, M. Ramesh, P. J. Uggowitzer, R. Spolenak, Precipitation strengthening of nb-stabilized tp347 austenitic steel by a dispersion of secondary $\mathrm{nb}(\mathrm{c}, \mathrm{n})$ formed upon a short-term hardening heat treatment, Materials Science and Engineering: A 647 (2015) 294-302.

[63] M. Arbuzov, S. Golub, M. Karpets, Structure of austenite ordering in chromium steels, Fizika Metallov i Metallovedenie 18 (4) (1986) 108-111.

URL https://inis.iaea.org/search/search.aspx?orig\{_\}q=RN : 18012665

[64] T. Badjuk, G. Kushma, O. Rybajlo, Temperature and concentration depencence of the unit cell dimensions of Fe-Cr solid solutions, Izvestiya Vysshikh Uchebnykh Zavedenii, Chernaya Metallurgiya 17 (1974) 126 - 128.

[65] J. Hinks, J. Van Den Berg, S. Donnelly, MIAMI: Microscope and ion accelerator for materials investigations, Journal of Vacuum Science \& Technology A: Vacuum, Surfaces, and Films 29 (2) (2011) 021003.

[66] G. Greaves, A. Mir, R. Harrison, M. Tunes, S. Donnelly, J. Hinks, New microscope and ion accelerators for materials investigations (MIAMI-2) system at the University of Huddersfield, Nuclear Instruments and Methods in Physics Research Section A: Accelerators, Spectrometers, Detectors and Associated Equipment 931 (2019) 37 - 43. doi: https://doi.org/10.1016/j.nima.2019.03.074. URL http://www.sciencedirect.com/science/article/pii/S0168900219304164

[67] R. E. Stoller, M. B. Toloczko, G. S. Was, A. G. Certain, S. Dwaraknath, F. A. Garner, On the use of SRIM for computing radiation damage exposure, Nuclear Instruments and Methods in Physics Research Section B: Beam Interactions with Materials and Atoms 310 (2013) 75-80. doi:10.1016/j.nimb.2013.05.008. URL http://www.sciencedirect.com/science/article/pii/S0168583X13005053

[68] C. M. Parish, L. N. Brewer, Multivariate statistics applications in phase analysis of STEM-EDS spectrum images, Ultramicroscopy 110 (2) (2010) 134-143. doi:10.1016/j.ultramic.2009.10.011

URL http://dx.doi.org/10.1016/j.ultramic.2009.10.011

[69] C. M. Parish, K. Wang, P. D. Edmondson, K. A. Terrani, X. Hu, R. L. Seibert, Y. Katoh, Combining Transmission Kikuchi Diffraction and Scanning Transmission Electron Microscopy for Irradiated Materials Studies, Microscopy and Microanalysis 23 (S1) (2017) 2218-2219. doi:10.1017/S1431927617011758.

[70] S. D. Brandi, C. G. Schön, A Thermodynamic Study of a Constitutional Diagram for Duplex Stainless Steels Journal of Phase Equilibria and Diffusion 38 (3) (2017) 268-275. doi:10.1007/s11669-017-0537-8 URL http://link. springer.com/10.1007/s11669-017-0537-8

[71] K. Hack (Ed.), The SGTE casebook: thermodynamics at work, The institute of materials, London, 1997.

[72] C. Balea, E. Bélislea, P. Chartranda, S. Decterova, G. Erikssonb, K. Hackb, I. Junga, Y. Kanga, J. Melançona, A. Peltona, et al., Factsage thermochemical software and databases_recent developments, Calphad 33 (2) (2009) 
295-311.

[73] S. Jin, L. Guo, F. Luo, Z. Yao, S. Ma, R. Tang, Ion irradiation-induced precipitation of cr23c6 at dislocation loops in austenitic steel, Scripta Materialia 68 (2) (2013) 138-141.

[74] R. W. Balluffi, S. M. Allen, W. C. Carter, Diffusion in Multicomponent Systems, in: Kinetics of Materials, John Wiley \& Sons, Inc., Hoboken, NJ, USA, 2005, pp. 131-144. doi :10.1002/0471749311.ch6. URL http://doi.wiley.com/10.1002/0471749311.ch6

[75] R. Sizmann, The effect of radiation upon diffusion in metals, Journal of Nuclear Materials 69-70 (C) (1978) 386412. doi:10.1016/0022-3115(78)90256-8

[76] T. H. Blewitt, R. R. Coltman, The Effect of Neutron Irradiation on Metallic Diffusion, Phys. Rev. 85 (2) (1952) 384. doi:10.1103/PhysRev.85.384. URL https://link.aps.org/doi/10.1103/PhysRev.85.384

[77] Y. Adda, M. Beyeler, G. Brebec, Radiation effects on solid state diffusion, Thin Solid Films 25 (1) (1975) $107-156$. doi:10.1016/0040-6090(75)90251-5. URL https://www.sciencedirect.com/science/article/pii/0040609075902515

[78] F. V. Nolfi, Phase transformations during irradiation, Applied Science Publishers, 1983.

[79] A. D. Marwick, Segregation in irradiated alloys : The inverse Kirkendall effect and the effect of constitution on void swelling, J. Phys. F: Metal Phys 8 (9). URL http://iopscience.iop.org/article/10.1088/0305-4608/8/9/008/pdf

[80] A. Gusak, K. Tu, Interaction between the kirkendall effect and the inverse kirkendall effect in nanoscale particles, Acta Materialia 57 (11) (2009) 3367-3373.

[81] K. K. Chawla, M. A. Meyers, Mechanical behavior of materials, Cambridge Unversity Press, Cambridge-MA, 1999.

[82] K. G. Field, X. Hu, K. C. Littrell, Y. Yamamoto, L. L. Snead, Radiation tolerance of neutron-irradiated model FeCr-Al alloys, Journal of Nuclear Materials 465 (2015) 746-755. doi:10.1016/j . jnucmat.2015.06.023 URL http://www.sciencedirect.com/science/article/pii/S0022311515300489?via\{\%\}3Dihub

[83] S. M. Tavares, R. F. de Noronha, M. R. da Silva, J. M. Neto, S. Pairis, $475{ }^{\circ} \mathrm{C}$ embrittlement in a duplex stainless steel UNS S31803, Mater. Res. 4 (2001) 237 - 240.

[84] W. M. Rainforth, M. P. Black, R. L. Higginson, E. J. Palmiere, C. M. Sellars, I. Prabst, P. Warbichler, F. Hofer, Precipitation of $\mathrm{NbC}$ in a model austenitic steel, Acta Materialia 50 (4) (2002) 735-747. doi:10.1016/ S1359-6454(01) 00389-5.

[85] E. J. Palmiere, F. Bai, R. Poths, J. Turner, V. Nagarajan, B. P. Wynne, M. W. Rainforth, The use of model systems based on Fe-30\% Ni for studying the microstructural evolution during the hot deformation of austenite, in: Materials Science Forum, Vol. 638, Trans Tech Publ, 2010, pp. 2694-2699. 


\section{Contents}

\begin{tabular}{lll}
\hline 1 & Introduction & 1
\end{tabular}

2 Materials and Methods $\quad 4$

2.1 The studied alloy and sample preparation $\ldots \ldots \ldots \ldots$. . . . . . . . . 4

2.2 In situ TEM ion irradiation at the MIAMI facilities $\ldots \ldots \ldots$

2.3 Post-irradiation characterisation $\ldots \ldots \ldots \ldots \ldots$

2.4 Thermodynamic calculations $\ldots \ldots \ldots \ldots \ldots$

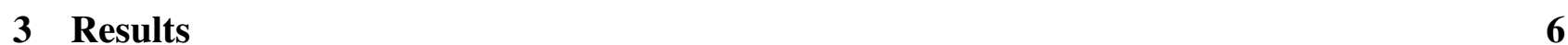

4 Discussion 12

4.1 The decomposition of the $\gamma$-Fe and the formation of the Cr-rich $\alpha$ ' under in situ TEM heavy ion irradiation . . . . . . . . . . . . . . . . . . 12

4.2 The impact of the $\alpha^{\prime}$ formation in the steel and the role of Nb-stabilisation . . . . . . 14

\begin{tabular}{lll}
\hline 5 & Conclusions & 15
\end{tabular}

\begin{tabular}{lll}
\hline & Data Availability & 16
\end{tabular}

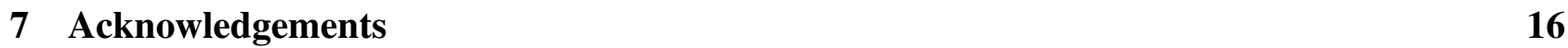

